\title{
The Use of Self-Help Strategies in Obesity Treatment. A Narrative Review Focused on Hypnosis and Mindfulness
}

\author{
Marianna Pellegrini ${ }^{1} \cdot$ Sara Carletto $^{2} \cdot$ Elena Scumaci $^{1} \cdot$ Valentina Ponzo $^{1} \cdot$ Luca Ostacoli $^{3} \cdot$ Simona Bo $^{1}$
}

Accepted: 21 May 2021 / Published online: 29 May 2021

(C) The Author(s) 2021

\begin{abstract}
Purpose of Review The aim of this narrative review was to summarize the evidence evaluating the possibilities and limitations of self-hypnosis and mindfulness strategies in the treatment of obesity.

Recent Findings Psychological factors, such as mood disorders and stress, can affect eating behaviors and deeply influence weight gain. Psychological approaches to weight management could increase the motivation and self-control of the patients with obesity, limiting their impulsiveness and inappropriate use of food. The cognitive-behavioral therapy (CBT) represents the cornerstone of obesity treatment, but complementary and self-directed psychological interventions, such as hypnosis and mindfulness, could represent additional strategies to increase the effectiveness of weight loss programs, by improving dysfunctional eating behaviors, self-motivation, and stimulus control.

Summary Both hypnosis and mindfulness provide a promising therapeutic option by improving weight loss, food awareness, self-acceptance of body image, and limiting food cravings and emotional eating. Greater effectiveness occurs when hypnosis and mindfulness are associated with other psychological therapies in addition to diet and physical activity. Additional research is needed to determine whether these strategies are effective in the long term and whether they can be routinely introduced into the clinical practice.
\end{abstract}

Keywords Hypnosis $\cdot$ Mindfulness $\cdot$ Obesity $\cdot$ Self-conditioning $\cdot$ Self-help

\section{Introduction}

Obesity is a public health burden [1]. Excess weight is associated with an increased risk for cardiometabolic diseases, cancer, and mortality [2] as well as a range of negative biopsychosocial outcomes and psychiatric symptoms, such as depression and anxiety [3]. The physiopathology of obesity is complex, involving the deregulation of appetite and energy

This article is part of the Topical Collection on Psychological Issues

Simona Bo

simona.bo@unito.it

1 Department of Medical Sciences, University of Torino, c.so AM Dogliotti 14, 10126 Torino, Italy

2 Department of Neuroscience "Rita Levi Montalcini", University of Torino, Torino, Italy

3 Department of Clinical and Biological Sciences, University of Torino, Torino, Italy metabolism, genetic, metabolic, biochemical, cultural, and psychosocial factors [4].

Unhealthy diets and poor exercise are considered the main environmental causes of excess weight; psychological factors can indeed heavily influence weight gain [5]. Stress and mood disorders have been linked to increased search for highdensity foods, decreased exercise, and altered eating behaviors [5]. "Emotional eating" is the inclination to eat in response to negative emotions, and "external eating" is the tendency to eat in response to external food cues; these behaviors are associated with unhealthy food choices and weight gain [6]. Furthermore, higher rates of depression, low self-esteem, anxiety, eating disorders (binge eating disorder, night eating syndrome, etc.), and impaired health-related quality of life are reported in individuals with obesity [7]. The reward circuits seem to be altered, with a preference for immediate rewards (e.g., high-fat, high-carbohydrate, salty foods) over long-term benefits (e.g., weight management) [8]. Uncontrolled daily stress may alter brain reward/motivation pathways involved in seeking hyperpalatable foods [9]. Indeed, inappropriate 
eating behaviors may be the result of a poor inhibitory control and hedonic homeostatic dysregulation, which may predispose to overeating palatable food in the absence of hunger [8], up to a condition of food addiction with greater emotion dysregulation, impulsivity, and food cravings [10]. The conditioning model of food cravings states that cravings can develop from pairing consumption of certain foods with external (e.g., watching television) or internal (e.g., feeling sad) stimuli [11].

The management of obesity usually includes lifestyle intervention only as the first approach, even if, in specific cases, based on the severity of the clinical condition, pharmacotherapy may be necessary early for the patient care. The attrition from weight management programs, however, affects most patients [12], and obesity treatment achieves poor results, with a high rate of relapse and weight recovery [2]. The search for approaches addressing the associated psychological problems and potentially increasing the motivation and self-control of the patients with obesity, limiting their impulsiveness and inappropriate use of food, are therefore important. Psychological interventions, particularly behavioral and cognitivebehavioral strategies, have been reported to be beneficial on weight loss in adults with overweight and obesity, especially when combined with dietary and exercise strategies [13]. The cognitive-behavioral therapy (CBT) has proven to be effective in determining weight loss by increasing healthy eating and exercise, improving psychologically related eating behaviors (i.e., cognitive restraint and emotional eating) [14] as well as cognitive factors, such as self-motivation, self-monitoring, and stimulus control $[15,16]$. Self-regulation (or self-control) can be defined as the suppression of a behavioral impulse toward a "lower-level" goal in the interest of pursuing a "higherlevel" goal [17]. Thus, dietary, and physical activity adherence demands self-regulation, which depends on the ability to maintain a continued awareness of behavior. The lack of this awareness and its consequences result in "mindless" eating and activities [16].

A great interest is related to self-directed psychological interventions that do not require the constant presence of a health professional ("self-help") [18], while employing the use of manuals, commercial products, technology, supportive peers, or occasional professional assistance [19]. These strategies aim to train patients in skills that enhance self-control such as goal setting, regulation, self-monitoring and evaluation, problem solving skills, and coping strategies for highrisk situations [17]. Several therapeutic approaches alone or in combination include psychodynamic, behavioral, cognitivebehavioral, mindfulness, and hypnotic therapy. The purpose of this narrative review is to focus on the application of hypnotherapy and mindfulness as self-help approaches in the treatment of obesity, replacing or supporting CBT.

\section{Methods}

The following databases were queried: PubMed (National Library of Medicine), Psychological Information Database Medical, Psychiatry, Mental Health Disorders (PsycInfo), Cochrane Library. The search strategy was performed using the following keywords: obesity OR overweight OR weight loss AND self-conditioning, self-control, self-help, self-regulation, strategies, hypnosis, hypnotherapy, hypno-behavioral therapy, mindfulness, cognitive behavioral therapy, psychological treatment, behavioral education. The filters "humans" and "adults" were used. Hand searching the references of the identified studies and reviews was carried out too.

\section{Hypnosis}

\section{History and Definitions}

Hypnosis has been considered as the oldest psychotherapy, being practiced by the ancient Egyptians since the fifteenth century BC. The rediscovery of hypnosis in 1700 s is due to the German doctor F.A. Mesmer who noted beneficial effects on the patient discomfort by entering into empathic resonance with him [20]. In 1841 the English doctor J. Braid introduced the term "hypnotism," based on the physiology of the brain [21, 22]. Due to the theories of J.M. Charcot and his most famous student, S. Freud, who considered the hypnosis as a pathological phenomenon, an artificial hysterical neurosis with a limited therapeutic value, the hypnotic method was abandoned [20, 23, 24]. During the world wars, hypnosis experienced a renewed interest, as it was applied to treat the war traumatic neuroses. More recently, the psychiatrist M. Erickson (1901-1980), by elaborating the concept of the unconscious, applied the clinical hypnosis in the re-elaboration of negative or traumatic events associated with adverse symptoms or diseases [20-25].

Although hypnosis acquired scientific dignity among scientists and clinicians, no agreement on its definition has been achieved [20, 25]. The British Psychological Society defines "hypnosis" as a waking state in which the individual attention is focused away from his/her surroundings and absorbed by inner experiences such as feelings, cognitions, and imagery, which can be influenced by the interaction with a "hypnotist" [26]. According to the American Psychological Association, hypnosis is a procedure during which a hypnotist guides the subject to respond to suggestions for changes in subjective experience, alterations in perceptions, sensations, emotions, thoughts, or behaviors [27, 28]. The neo-Ericksonians defined hypnosis as a strategy that explores the deeper causes of the disorders rather than aiming at the remission of the symptoms; indeed, during the hypnotic trance, the unconscious offers the possibility of solutions to problems or conflicts [20, 25-29]. 


\section{The Rationale for Using Hypnosis in the Treatment of Obesity}

Hypnosis has been successfully used as an anti-stress and relaxation strategy to treat many chronic conditions exacerbated by negative emotions and social factors (e.g., quitting smoking [30]), chronic digestive diseases [31], cancerrelated symptoms in palliative care setting [32], acute and chronic pain [33]. Individuals can practice hypnosis on their own (self-hypnosis); hypnotherapy (either alone or in addition to other psychotherapies, such as cognitive-behavioral techniques) has been involved in the obesity multidimensional approach to increase self-control, to improve exercise levels, to boost self-esteem, and to strengthen motivation in changing eating habits [34]. Stress-induced overeating and reward from comfort food can be considered an attempt at self-medication to relieve the negative emotions and depressive state associated with chronic psychological stress [35]. Hypnosis as a strategy for stress management could be an important component in the approach toward stress-induced overeating and impaired reward mechanisms characterizing many patients with obesity (Fig. 1).

\section{Studies on Hypnosis and Weight Management}

The application of hypnosis for weight reduction has been reported in the literature since the 1950s [36]. Hypnotized state was initially induced by experienced therapists; indeed, self-hypnosis and the autonomous use of supplemental materials (i.e., home audio tapes) have been encouraged from the earliest years of hypnotherapy to reinforce the therapist suggestions and provide additional support after the formal treatment completion [37]. With hypnotic suggestions (i.e., verbal, and non-verbal communications), people can be taught to reduce food intake, eat at fixed times and places, restrict the purchase of food supplies, and evoke aversive responses, such as sickness and disgust, when eating high-calorie foods [34]. Clinical trials comparing cognitive-behavioral therapy alone versus cognitive behavioral therapy plus hypnosis for various conditions, including obesity, were first reviewed in 1990s in two meta-analyses [38, 39]. Kirsch [38] analyzed 6 weight loss trials and reported an improvement in weight loss with hypnosis (weighted mean effect size $=1.96$ ) and no weight regain after hypnosis even at 2-year follow-up. However, this meta-analysis [38] displayed several methodological limitations (lack of data availability for some studies, high risk of bias of the included research, short follow-up for most of the included studies, high drop-out rates). Allison [39] reanalyzed the same 6 weight loss trials and found that hypnosis, as an adjunct to CBT, produced only a small effect on average (weighted mean effect size $=0.28$ ) [39]. Kirsch [40], then, re-conducted the metanalysis and reported an effect size of 0.98 , which was different from previous results, but still indicative of a benefit from the combination of hypnosis with CBT. The correlation between the efficacy of hypnosis in weight loss program and the degree of hypnotizability is

\section{HYPNOSIS}

\section{ACTIONS: \\ - hypnotic suggestions \\ - relaxation \\ - visual images \\ - self-control \\ - self-esteem}

\section{OUTCOMES:}

Improvement of:

- stress-induced overeating

- motivation in healthy eating habits

(i.e., reduced food intake, eating at

fixed times and places, evoke aversive

responses to high-calorie foods)

- exercise levels

- weight loss

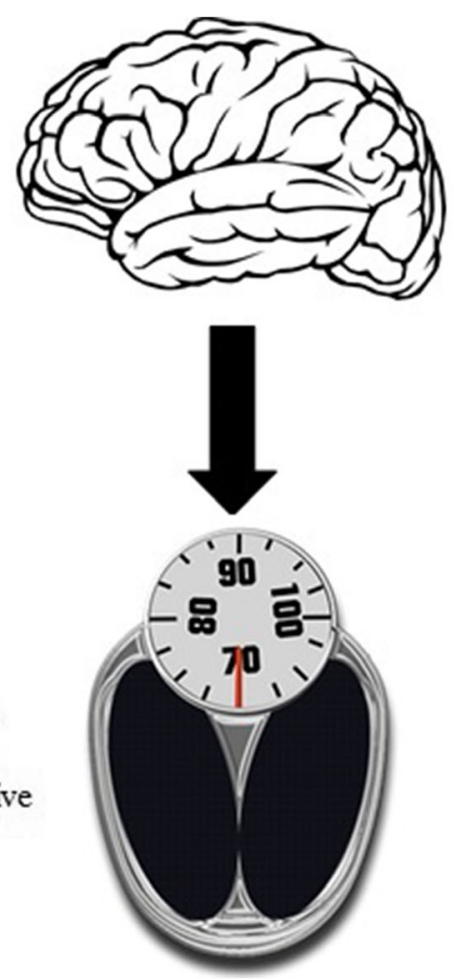

Fig. 1 Hypnosis and mindfulness as strategies for stress management in obesity treatment

\section{MINDFULNESS}

\author{
ACTIONS: \\ - awareness of \\ sensations \\ emotions \\ thoughts \\ sensory properties of food \\ - self-regulation \\ - self-acceptance
}

\section{OUTCOMES:}

Improvement of:

- problematic eating behaviors

- emotional eating

- binge eating

- eating-related psychological distress

(i.e., anxiety, depression, stress)

- weight loss 
highly controversial, since not all studies found such a relationship. The mechanism by which hypnotherapy might work is the processing of problems related to nutrition through the detection and integration of neglected resources, relaxation, hypnotic suggestions, and visual images [41]. In 1986, a RCT assessed in 60 overweight women the effectiveness of 1-month hypnosis on weight loss, either alone (Hy; $n=17$ patients) or plus audiotapes (Hy-T; $n=17$ patients), compared to a wait-listed control group ( $n=20$ patients) [42]. When compared to controls, both the Hy and Hy-T interventions significantly reduced body weight after 1 month $(-3.62 \mathrm{~kg} \mathrm{Hy}$; $-2.96 \mathrm{~kg} \mathrm{Hy}-\mathrm{T} ;+0.68 \mathrm{~kg}$ controls; $p<0.01)$ and 6 months $(-7.76 \mathrm{~kg} \mathrm{Hy} ;-8.00 \mathrm{~kg}$ Hy-T; $-0.22 \mathrm{~kg}$ controls; $p<0.01)$ [42]. In 1998, 60 individuals with obesity and sleep obstructive apnea ( $80 \%$ males) were randomized to receive either hypnotherapy for the reduction of stress or hypnotherapy for reducing energy intake or dietary advice alone for 18 months [43]. All the three groups lost 2-3\% of their initial body weight at 3 months, while, at 18 months, only hypnotherapy for stress reduction determined a significant $(p<0.02)$, but small weight loss $(3.8 \mathrm{~kg})$ compared to baseline. Noteworthy the dropout rate was $25 \%$ [43], thus requiring caution in the interpretation of these results. In 2014, two types of hypnotherapies were compared in 60 females with obesity by a parallel RCT: hypno-behavioral therapy (HypBe) (a combination of hypnotherapy - i.e., hypnotic trances - plus behavioral therapy-i.e., behavioral exercises, role-playing, and homework) and hypno-energetic (HypEn) therapy (a therapy enhancing the hypno-behavioral strategies with acupressure, that is, the manual stimulation of acupuncture in the related points) [44]. Both treatments consisted of 12 sessions lasting $120 \mathrm{~min}$ over an 8.5-month period, and participants were assessed at the beginning and the end of the treatment, as well as after 6month follow-up. Regardless of the hypnotherapy received, initial weight and BMI were significantly reduced from the beginning to the end of treatment $(-2.4 \mathrm{~kg}, p<0.01$ and -0.8 $\mathrm{kg} / \mathrm{m}^{2}, p<0.01$ within the HypBe group; $-3.1 \mathrm{~kg}, p<0.01$ and $-1.1 \mathrm{~kg} / \mathrm{m}^{2}, p<0.01$ within the HypEn group), but significant weight and BMI reductions from the end of treatment to the follow-up $\left(-2.2 \mathrm{~kg}, p<0.01\right.$ and $\left.-0.8 \mathrm{~kg} / \mathrm{m}^{2}, p<0.01\right)$ and significant improvements in eating behaviors, and several aspects of body concept, such as physical efficiency, self-acceptance of the body/physical appearance/sexuality, were observed in the HypEn group only [44]. A systematic review of 5 metaanalyses of RCTs demonstrated the efficacy of medical hypnosis in the reduction of pain and emotional stress during medical interventions (34 RCTs, 2597 patients) [45]. Indeed, the application of hypnotherapy aims to emotionally restructure stressful events and sensations and cognitive-affective patterns (through minimization, reinforcement, new conditioning), and to improve problem management by giving the patient access to his own resources, thus facilitating changes in behaviors [45]. Milling performed two meta-analyses comparing hypnosis with a control condition including standard care, attention control, or no-treatment (14 trials) and CBT alone with CBT augmented by hypnosis (11 trials) over a relatively short span of time (average length of the hypnosis interventions in the two samples of trials $\approx 6.5$ weeks) [46••]. Hypnosis demonstrated to be more effective in producing weight loss when compared to the control condition (effect sizes $=1.58 \mathrm{lb}, p \leq 0.001$ at the end of the active treatment in 14 trials, and $0.88 \mathrm{lb}, p \leq 0.001$ in 6 trials with longer followup) [46••]. Similarly, hypnosis plus CBT compared to CBT alone induced an increased weight loss (effect sizes $=0.25 \mathrm{lb}$, $p \leq 0.05$ in 11 trials at the end of the intervention and $0.80 \mathrm{lb}$, $p \leq 0.001$ in 12 trials with longer follow-up of $\approx 12$ weeks) [46*0]. Recently, a RCT evaluated the effectiveness of selfhypnosis added to standard care in determining weight loss in patients with severe obesity [47]. A rapid-induction phase was used to allow the patient to go into hypnosis in a few minutes, then participants were trained to enter into hypnosis in complete autonomy daily, before each meal [47]. In the selfhypnosis arm, a significant improvement in quality of life, satiety, and inflammation occurred with respect to controls with standard care, without a significant difference in weight loss $(-6.5-\mathrm{kg}$ intervention group, $n=44$ patients; $-5.6-\mathrm{kg}$ control group, $n=42$ patients; $p=0.79$ ). Indeed, within the intervention group, habitual hypnosis users showed a greater weight loss than those who practiced self-hypnosis less frequently $(-9.6 \mathrm{~kg}, \geq$ once per day; $-7.5 \mathrm{~kg}<$ once per day; +0.2 rarely or none; $p=0.001$ ) [48]. The same research group reported an acute effect on the brain peptides involved in the hunger/satiety regulation after a hypnosis-induced hallucinated meal in highly hypnotizable individuals, thus suggesting the potential role of hypnosis on central appetite modulation [49•].

In conclusion, 11 randomized trials about the effect of hypnosis as an adjunctive strategy to lose weight were published; out of them, 9 [42-44, 48, 50-54] reported overall beneficial effects, even if mild or moderate and more evident after a longer follow-up [42, 44, 50, 51, 53], while only $2[55,56]$ failed to find any benefits.

A few ongoing trials studying the use of hypnosis in the treatment of obesity $[57,58]$ are reported in Table 1 .

\section{Limitations of Hypnosis as Self-Help Strategies to Lose Weight}

Although hypnosis has been reported as a successful approach to promote weight loss in addition to lifestyle and/or psychological interventions, the overall number of related studies was low, and most trials were very old, i.e., published in the 1980s $[42,50-53,55,56]$. Furthermore, the methodological quality was limited; most studies had an observational design, a low number of enrolled patients, short duration of the intervention, and only a few reported follow-up data. Patient recruitment 
might be a challenge in hypnosis-based interventions, the individual hypnotizability is still a highly debated question [41], and the available papers reported an increased female participation, with high rates of drop-out or discontinuation of the intervention [43, 44, 48]. Due to the small sample sizes, some studies might lack the statistical power to detect differences between the interventions [54], and divergent effect size values were reported in meta-analyses [38-40, 44, 46]. Therefore, at present, the evidence toward the efficacy of hypnosis as a strategy for losing weight is scarce.

\section{New Technologies}

Due to the great interest in self-managed strategies that could help individuals to lose weight, an increasing number of internet websites, videos, and smartphone applications dedicated to hypnosis are available. A review of 407 hypnosis applications for smartphones and tablets reported that the most frequently proposed goal was weight loss $(22.6 \%)$, by delivering hypnosis via audio track, visual means (i.e., reading the text of a hypnosis script), or both [59]. However, only a few applications mentioned the hypnotist being a "doctor," and none reported being evidence-based (empirically tested); therefore, concern about their safety and efficacy was reported [59]. Further rigorous studies to support the effectiveness of hypnosis applications are needed in order to develop scientifically validated tools for consumers.

\section{Mindfulness}

\section{History and Definitions}

Mindfulness practice has a very long history, dating back to over 2500 years ago. It was part of different religious and secular traditions, such as Hinduism, Buddhism, and yoga [60], but became known in the West in the 1970s thanks to Kabat-Zinn, who abstracted the concept from its original religious context [61]. Mindfulness could be defined as a nonjudgmental awareness and acceptance of one's moment-tomoment experience [62]. As described by Bishop [63], mindfulness consists of two main components: the self-regulation of attention and a particular orientation toward the experience. Self-regulation of attention concerns the non-judgmental observation and awareness of physical sensations, affective states, and thoughts as they arise. Orientation to experience refers to the attitude of acceptance and curiosity toward one's experience. Mindfulness has been described as a set of skills that can be learned through practices like meditation and therapeutic interventions, the Mindfulness-Based Interventions (MBIs). MBIs are usually conducted in groups, and participants are guided by instructors who have received specific training and have a personal meditation background, but the 
fundamental and distinctive element remains the experiential learning that each participant acquires during the course by means of daily training.

Mindfulness-Based Stress Reduction Program (MBSR) training is the most common form of MBIs and consists of eight 2.5-h weekly sessions and one 7-h day of silence [62, 64]. This training aims at improving the capacity of attention and non-judgmental awareness and could teach people to break with the maladaptive patterns of thinking and behavior. These maladaptive strategies are believed to contribute to the onset and maintenance of many emotional disorders [63]. Alongside with MBSR, Segal [65] proposed a MindfulnessBased Cognitive Therapy (MBCT) program, that is an approach which brings together elements from MBSR and from Cognitive Therapy, aiming to prevent depressive relapse and depressive symptoms. Mindfulness-Based Eating Awareness Training (MB-EAT) is a specific mindful eating training program integrating MBSR and CBT components [66, 67]. It was originally designed for binge-eating disorder, but it was also implemented in non-clinical populations to promote weight loss. MB-EAT is aimed at improving eating behavior and more generally at developing a healthier and more balanced attitude toward food. Attention is also paid to stress related to eating and dysfunctional modes of eating behavior (e.g., emotional, and external eating).

\section{The Rationale for Using Mindfulness-Based Interventions in the Treatment of Obesity}

Mindfulness practice has been repeatedly reported to decrease global psychological distress and improve overall mental health $[68,69]$. MBIs have also shown their effectiveness in decreasing anxiety, as well as improving depressive symptoms [70], by ameliorating self-regulation [71].

Different dysfunctional eating behaviors, such as binge eating, emotional eating, external eating, and eating in response to food cravings, have been linked also to weight regain after successful weight loss [72]. Furthermore, the distracted and unaware eating impairs the memory of the meal and increases further food intake, suggesting that the attentive and mindful experience of a meal is necessary for adequate satiation mechanisms and proper inhibitory controls [35]. The different theoretical models for explaining problematic eating behaviors suggest the association between maladaptive responses to internal and external stimuli and the dysregulation of eating behaviors [72, 73]. Several studies have also indicated stress and negative emotions among the principal determinants of unhealthy eating behavior [74-76]. As mindfulness and mindful eating promote self-regulation by better management of negative emotional states and stress, and promote awareness of the sensations associated with eating, these trainings can be used as strategies to help people to diminish the reactivity to dysfunctional food cues (e.g., advertising, boredom, anger, anxiety) [77] and to favor weight control (Fig. 1).

\section{Studies on Mindfulness-Based Interventions and Weight Management}

The first integrative review on the role of MBIs in the treatment of obesity was published in 2013 [78]. While denoting the paucity of studies conducted up to that time, this review provided a general overview of the use of MBIs either as stand-alone treatment or as complementary to other traditional approaches in the treatment of obesity and eating disorders. O'Reilly [72] conducted a literature review to investigate the effects of MBIs to treat obesity-related eating behaviors (e.g., binge eating, emotional eating, and external eating) on 21 primary studies, showing that in $86 \%$ of the included studies there was an improvement in targeted eating behaviors. The first systematic review [79] included 14 interventional studies and found a reduction in binge and emotional eating after mindfulness meditation training. Another systematic review [80] reported that 13 of the 19 included studies showed a beneficial effect of MBIs on weight loss, although the specific degree to which increased mindfulness was a mechanism leading to weight loss was not identified. In fact, mixed results were found regarding the association between mindfulness change (i.e., after MBIs) and weight loss. Further research to investigate the specific mechanisms involved in the relationship between mindfulness and weight loss was recommended. Tapper [81] attributed the beneficial effects of MBIs on weight loss and impaired eating behaviors to both the present moment awareness of the sensory properties of food that can reduce further food intake, and the decentering strategies that may help individuals resist desired foods. The first review that considered the change in mindfulness as a primary outcome and mindful eating as a measured variable was performed by Dunn in 2018 [82]; the authors strongly supported the use of mindfulness in weight management programs, also suggesting a potential benefit for the treatment of obesity. A very recent systematic review [83], including 9 RCTs, showed that in most of the included studies, there was a positive effect of MBIs on reducing emotional eating, binge eating, and weight and shape concern. The mechanisms of action highlighted were the increase in awareness of internal experiences and automatic patterns and the improvement in self-acceptance and emotional regulation, which led to a reduction of problematic eating behaviors. Moreover, to date six meta-analyses were published evaluating the efficacy of MBIs for weight management, obesity, and/or problematic eating behaviors. Overall, their results showed that MBIs have beneficial effects on both obesity-related eating behaviors [84, 85] and binge eating [86, 87]. In particular, moderate-to-large effect sizes (Hedge's g ranging from 0.70 to 1.08 ) were found for obesity-related eating behaviors $[84,85]$, while large effect 
sizes have been shown for binge eating (Hedge's g ranging from -0.90 to -1.08$)[86,87]$. The effect on weight loss was found to be moderate in both Carrière [84] and Rogers [85] meta-analyses, with Hedge's g $=0.42$ and Hedge's g $=0.47$, respectively. The greater effects on weight loss were found in studies that used a combination of informal and formal meditation practice rather than formal meditation practice alone [84]. In another meta-analysis [88], a significant weight loss effect of MBIs was found when compared with nonintervention controls (standardized mean difference: -0.348 $\mathrm{kg}, 95 \% \mathrm{CI}:-0.591$ to $-0.105, p=0.005$ ), showing that the MBI effect was similar to common diet programs. Lawlor [89] recently performed a network meta-analysis to evaluate the effect of third-wave cognitive behavior therapies for weight management. Their result pointed out that Acceptance and Commitment Therapy (ACT) intervention was the intervention with the greatest effect on weight loss as compared to standard behavioral programs, with long-lasting effects at 12- and 24-month follow-up. Moderate effects of MBIs were also revealed for the impact on eating-related psychological distress, with a Hedge's $g=0.64$ for depression and 0.62 for anxiety [85]. Several other trials on mindfulness in weight management are ongoing [90-92] (Table 2). Recent studies conducted in this area, which were not included in the reviews and meta-analyses above described, are shown in Table 3 [93-107]. Sixteen studies were retrieved, including 9 RCTs and 7 intervention studies without a control group. Overall, these studies showed promising findings supporting the effectiveness of MBIs to improve problematic eating behaviors and weight management.

\section{Limitations of Mindfulness as Self-Help Strategies to Lose Weight}

The main limitations of the research conducted so far are represented by the high heterogeneity of included cohorts and the different MBIs programs among the studies. Combining clinical and non-clinical populations in the same quantitative synthesis could be problematic as MBIs may exert different effects in these two groups [84]. It is very important to consider that different types of mindfulness training could be grouped under the "MBIs" label [84]. These include combined mindfulness and cognitive behavioral therapies, MBSR, mindful eating programs such as MB-EAT, thirdwave cognitive behavior therapies (e.g., ACT), dialectical behavior therapy-DBT, MBCT, compassion-focused therapyCFT, and other different combinations of mindfulness exercises. In addition, these interventions may vary in terms of therapeutic components, length, and time of practice requested to participants. Another main limitation is the use of small sample sizes and limited follow-up assessments. In order to strengthen the evidence and evaluate possible long-lasting effects, more research with larger sample sizes and with longer follow-ups is needed. More RCTs are also needed to compare MBIs with other active interventions (e.g., conventional diet programs, standard behavioral treatment, dietary counseling) in order to assess the specific effects of mindfulness on weight management and dysfunction eating behaviors. In this regard, few studies included a valid measurement of mindfulness skills [84, 87], which is fundamental to evaluate both the extent to which increased mindfulness is an active component of treatment and the underlying mechanisms by which MBIs may improve weight management and associated psychological factors [85-87].

\section{New Technologies}

Empirical evidence suggests that MBIs can be effectively delivered online, with significant effects in reducing stress, depression, anxiety, and in improving quality of life in both nonclinical and clinical samples [108, 109]. Lyzwinski performed two interesting reviews evaluating the quality and the effects of electronic MBIs for weight-related behaviors [76, 110]. They reviewed all the commercial mindful eating applications available on Apple iTunes until 2018 to evaluate their quality and the adherence of their contents to the fundamental tenets of mindful eating [110]. Most of the applications revealed a poor-quality score according to the Mobile App Rating Scale (MARS), and few were found to include the essential aspects of mindful eating, although they claimed to do so. Moreover, a systematic review assessed the effects of electronic MBIs for weight and weight-related behaviors [110]. Among the 21 included studies, MBSR protocol was used in 19 studies and mindful/intuitive eating interventions in the other two. Most of the electronic interventions were aimed at stress management, and only a few targeted at weight control. The results showed beneficial results for stress reduction. Based on this very limited number of studies, however, it was not possible to evaluate the impact of these online mindfulness trainings on weight management. Further studies that directly target weight-related behaviors and evaluate other types of mindfulness-based approaches are needed to establish the efficacy of online MBIs in this area.

\section{Similarities and Differences Between Hypnosis and Mindfulness}

Hypnosis and mindfulness are two distinct and independent strategies, each with its own theoretical and historical facets, which share some common mechanisms at both functional and neurobiological levels [111-113]. Both strategies employ attentional skills $[112,113]$ and use an attentional focus to develop the ability to be mindful (in mindfulness) or becoming immersed in suggestion-related experiences (in hypnosis) [111]. Based on these and other similarities (please refer to 


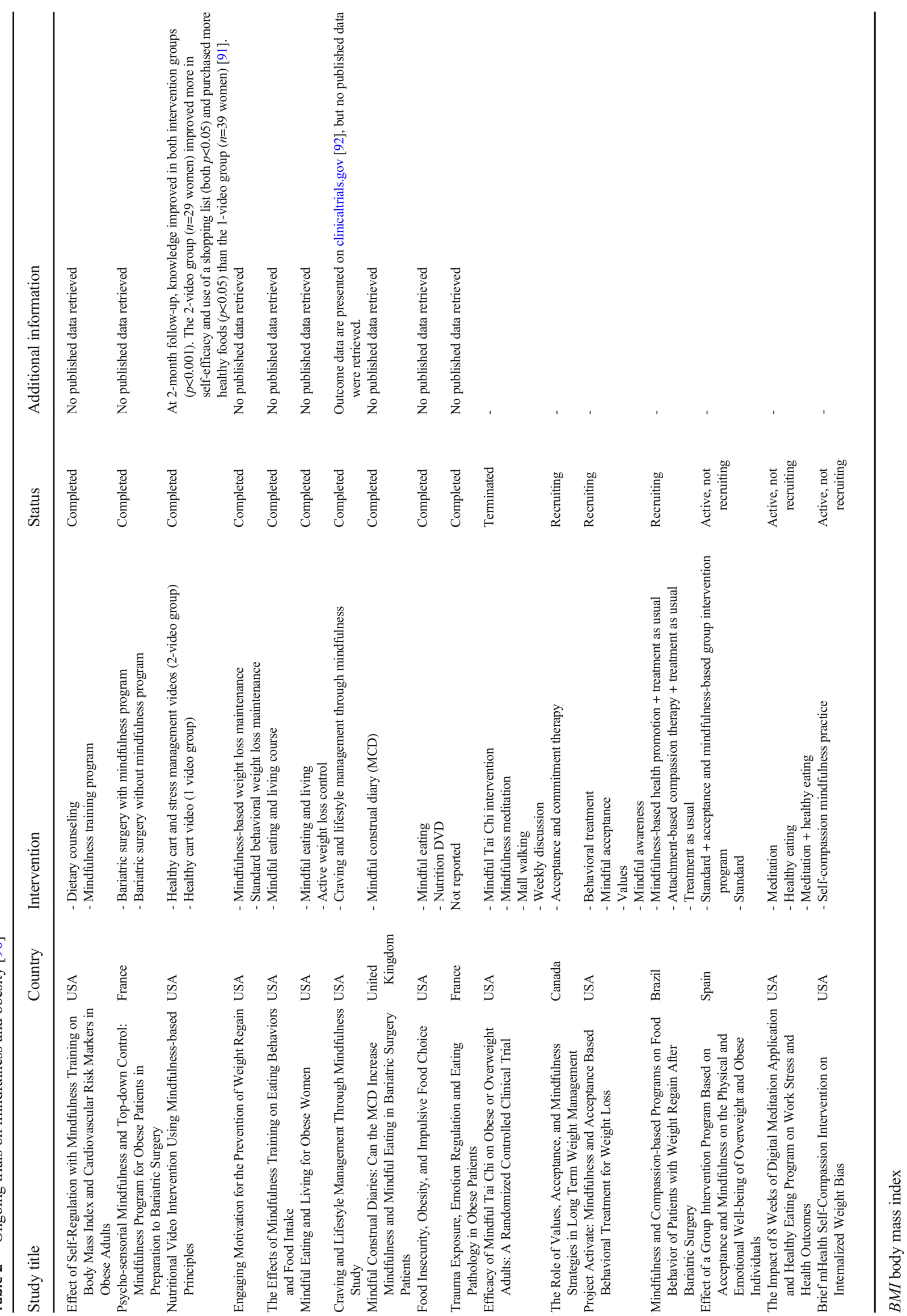




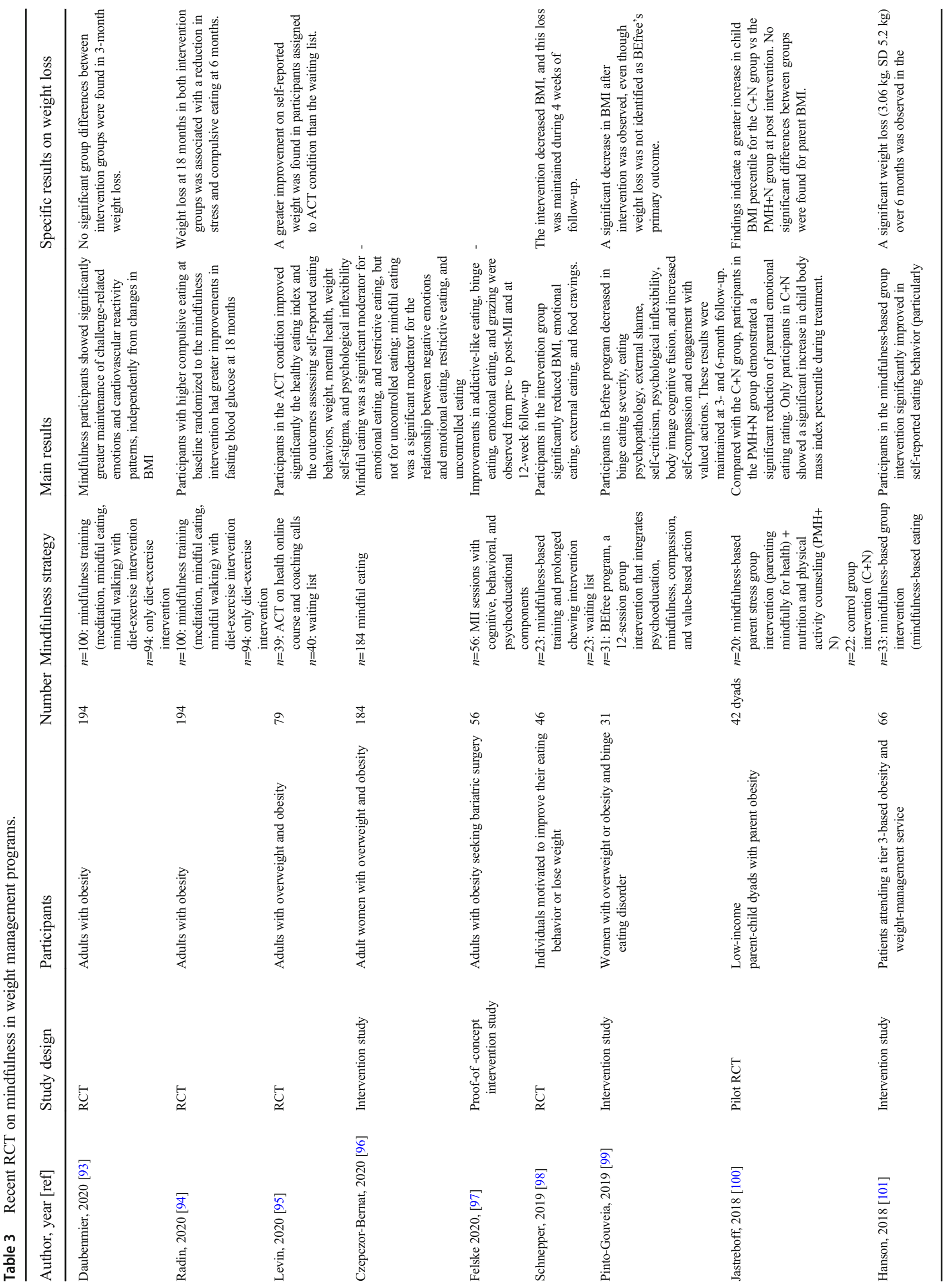




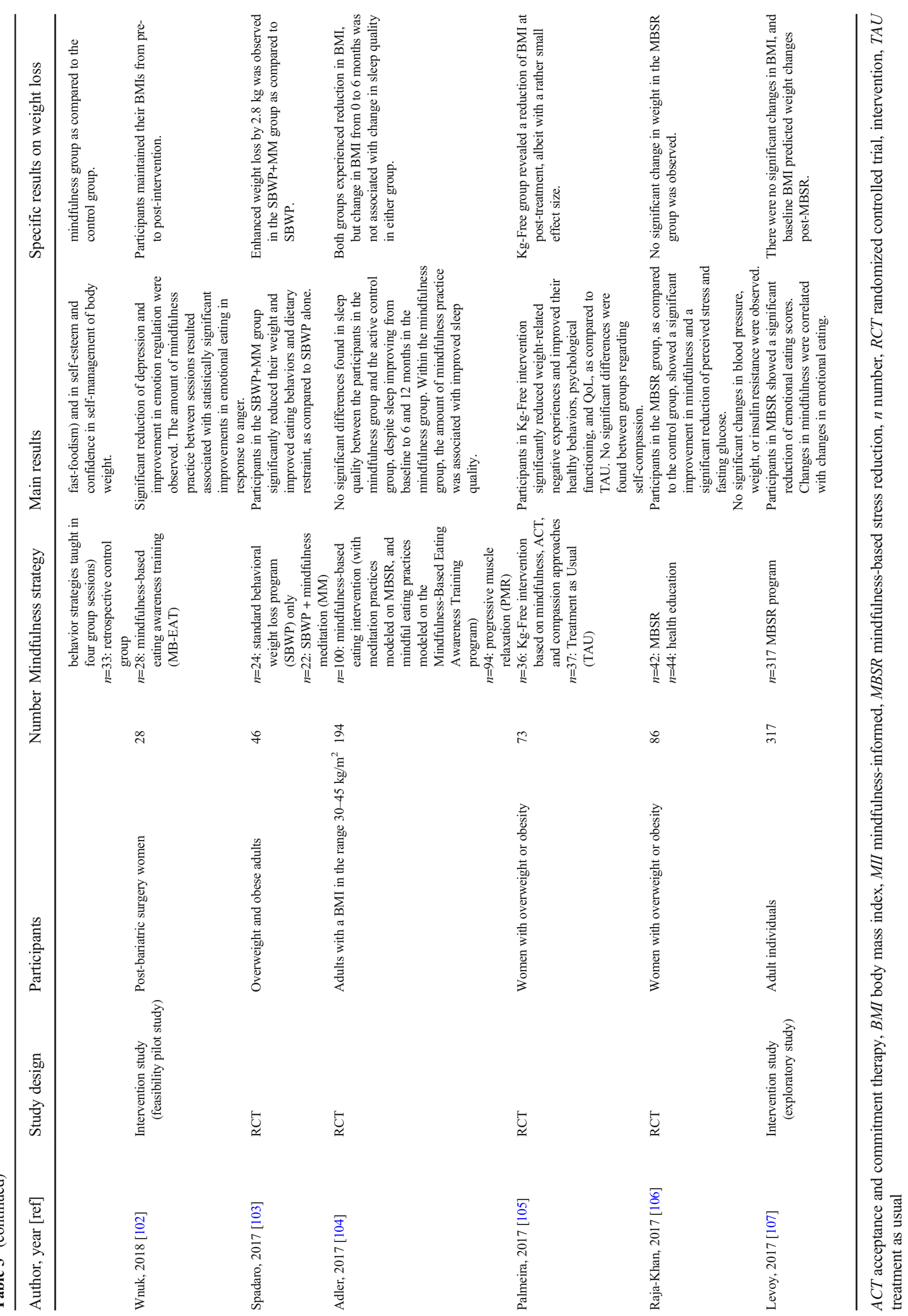


Otani et al. [112] for a comprehensive examination of common mechanisms between these two approaches), some authors have suggested to combine them, in order to use hypnosis to enhance the effects of mindfulness [114-116] and coining the term "mindful hypnotherapy" [117].

Other authors have instead underlined that mindfulness and hypnosis could not be considered as overlapping constructs $[111,112,118]$. As specified by Grover et al. [118], the purpose of hypnosis is to experience changes in consciousness and behavior as a result of suggestive induction. In contrast, the purpose of mindfulness is to notice what is happening in the unfolding experience of sensations, emotions, and thoughts, moment by moment, without the intention to promote an imminent change. Suggestion could be considered as a common mechanism of both strategies, but with different targets: mindfulness promotes a change in the relationship with the experience, while hypnosis fosters a change in the experience itself [118]. Recently, Grover et al. [118] have shown that higher levels of hypnotizability are associated with a reduction of mindfulness facets, in particular the ability to observe, non-react, and non-judge, suggesting that the two strategies have distinct effects and could therefore be offered according to the predominant characteristics of the subjects.

In conclusion, although the two approaches have a long tradition of use, it is only in recent years that clinicians and researchers have started to investigate their common aspects. Therefore, further research is needed to assess whether and how these two strategies can be combined to enhance overall clinical effectiveness.

\section{Conclusions}

Fighting the obesity epidemic is challenging due to the ineffectiveness of diet and exercise alone, so finding effective new strategies is mandatory. Due to the relevant psychological involvement in the pathogenesis of obesity, different psychological strategies applied alone or in combination seem to offer a greater chance of success. Hypnosis and mindfulness are ancient strategies that in recent years have gained renewed interest, due to the spread of the offer, the variety of therapeutic applications, and the flexibility of use, which also includes self-administration. Both hypnosis and mindfulness provided additional benefit in the treatment of obesity when applied in a weight management program with or without other psychological interventions; however, owing to the heterogeneity of hypnosis and mindfulness strategies and the short-term duration of most studies, the relative evidence is at present scarce. Additional research is needed to determine whether these strategies are effective in the long term and whether they can be routinely introduced into the clinical practice.
Abbreviations $A C T$, Acceptance and commitment therapy; $C B T$, Cognitive-behavioral therapy; $C F T$, Compassion-focused therapy; $D B T$, Dialectical behavior therapy; MARS, Mobile App Rating Scale; MBIs, Mindfulness-Based Interventions; $M B C T$, Mindfulness-Based Cognitive Therapy; $M B-E A T$, Mindfulness-Based Eating Awareness Training; $M B S R$, Mindfulness-Based Stress Reduction Program; $R C T$, Randomized controlled trial

Code Availability Not applicable.

Funding Open access funding provided by Università degli Studi di Torino within the CRUI-CARE Agreement.

\section{Declarations}

Conflicts of Interest All authors declare no conflict of interest.

Human and Animal Rights and Informed Consent This article does not contain any studies with human or animal subjects performed by any of the authors.

Ethics Approval Not applicable.

Open Access This article is licensed under a Creative Commons Attribution 4.0 International License, which permits use, sharing, adaptation, distribution and reproduction in any medium or format, as long as you give appropriate credit to the original author(s) and the source, provide a link to the Creative Commons licence, and indicate if changes were made. The images or other third party material in this article are included in the article's Creative Commons licence, unless indicated otherwise in a credit line to the material. If material is not included in the article's Creative Commons licence and your intended use is not permitted by statutory regulation or exceeds the permitted use, you will need to obtain permission directly from the copyright holder. To view a copy of this licence, visit http://creativecommons.org/licenses/by/4.0/.

\section{References}

Papers of particular interest, published recently, have been highlighted as:

- Of importance

-• Of major importance

1. Abarca-Gómez L, Abdeen ZA, Hamid ZA, Abu-Rmeileh NM, Acosta-Cazares B, Acuin C, et al. Worldwide trends in bodymass index, underweight, overweight, and obesity from 1975 to 2016: a pooled analysis of 2416 population-based measurement studies in 128.9 million children, adolescents, and adults. The Lancet. 2017;390:2627-42.

2. Bray GA, Kim KK, Wilding JPH. Obesity: a chronic relapsing progressive disease process. A position statement of the World Obesity Federation. Obes Rev. 2017;18:715-23.

3. Karasu SR. Psychotherapy-lite: obesity and the role of the mental health practitioner. Am J Psychother. 2013;67:3-22.

4. Lang A, Froelicher ES. Management of overweight and obesity in adults: behavioral intervention for long-term weight loss and maintenance. Eur J Cardiovasc Nurs. 2006;5:102-14.

5. Jang HJ, Kim BS, Won CW, Kim SY, Seo MW. The relationship between psychological factors and weight gain. Korean J Fam Med. 2020;41:381-6. 
6. Elfhag K, Morey LC. Personality traits and eating behavior in the obese: poor self-control in emotional and external eating but personality assets in restrained eating. Eat Behav. 2008;9:285-93.

7. Brennan L, Murphy KD, Garcia X de la P, Ellis ME, Metzendorf M-I, McKenzie JE. Psychological interventions for adults who are overweight or obese. Cochrane Database Syst Rev. 2016. Available at: http://www.cochranelibrary.com/cdsr/doi/10.1002/ 14651858.CD012114/full. Accessed 19 Dec 2020.

8. Robinson E, Roberts C, Vainik U, Jones A. The psychology of obesity: an umbrella review and evidence-based map of the psychological correlates of heavier body weight. Neurosci Biobehav Rev. 2020;1(19):468-80.

9. Yau YHC, Potenza MN. Stress and eating behaviors. Minerva Endocrinol. 2013;38(3):255-67.

10. Schulte EM, Gearhardt AN. Attributes of the food addiction phenotype within overweight and obesity. Eat Weight Disord. 2020. https://doi.org/10.1007/s40519-020-01055-7.

11. Myers CA, Martin CK, Apolzan JW. Food cravings and body weight: a conditioning response. Curr Opin Endocrinol Diabetes Obes. 2018;25:298-302.

12. Ponzo V, Scumaci E, Goitre I, Beccuti G, Benso A, Belcastro S, et al. Predictors of attrition from a weight loss program. A study of adult patients with obesity in a community setting. Eat Weight Disord. 2020. https://doi-org.bibliopass.unito.it/10.1007/s40519020-00990-9.

13. Shaw K, O'Rourke P, Del Mar C, Kenardy J. Psychological interventions for overweight or obesity. Cochrane Database Syst Rev. 2005;18:CD003818.

14. Jacob A, Moullec G, Lavoie KL, Laurin C, Cowan T, Tisshaw C, et al. Impact of cognitive-behavioral interventions on weight loss and psychological outcomes: a meta-analysis. Health Psychol. 2018;37:417-32.

15. Cosme D, Ludwig RM, Berkman ET. Comparing two neurocognitive models of self-control during dietary decisions. Soc Cogn Affect Neurosci. 2019;14:957-66.

16. Forman EM, Butryn ML. A new look at the science of weight control: how acceptance and commitment strategies can address the challenge of self-regulation. Appetite. 2015;84:171-80.

17. Johnson F, Pratt M, Wardle J. Dietary restraint and self-regulation in eating behavior. Int J Obes (Lond). 2012;36:665-74.

18. Hartman D. Confidence intervals and hypnosis in the treatment of obesity. J Heart Centered Ther. 2010;13:37-9.

19. Carels RA, Wott CB, Young KM, Gumble A, Darby LA, Oehlhof MW, et al. Successful weight loss with self-help: a stepped-care approach. J Behav Med. 2009;32:503-9.

20. Ellenberger HF. The discovery of the unconscious: the history and evolution of dynamic psychiatry. Basic Books; 1981.

21. Braid J. Neurypnology, or the rationale of nervous sleep, considered in relation with animal magnetism: illustrated by numerous cases of its successful application in the relief and cure of disease. 1843.

22. Braid J. Observations on trance: or human hybernation. Churchill; 1850.

23. Broussolle E, Gobert F, Danaila T, Thobois S, Walusinski O, Bogousslavsky J. History of physical and «moral» treatment of hysteria. Front Neurol Neurosci. 2014;35:181-97.

24. Kravis NM. James Braid's psychophysiology: a turning point in the history of dynamic psychiatry. Am J Psychiatry. 1988;145: 1191-206.

25. Short D. Conversational Hypnosis: conceptual and technical differences relative to traditional hypnosis. Am J Clin Hypn. 2018;61:125-39.

26. Heap M. Defining hypnosis: the UK experience. Am J Clin Hypn. $2005 ; 48: 117-22$.
27. Elkins G, Barabasz A, Council J, Spiegel D. Advancing research and practice: the revised APA division 30 definition of hypnosis. Int J Clin Exp Hypn. 2015;63:1-9.

28. Green JP, Barabasz AF, Barrett D, Montgomery GH. Forging ahead: the 2003 APA Division 30 definition of hypnosis. Int J Clin Exp Hypn. 2005;53:259-64.

29. Principi di teoreticità e di prassi della Psicoterapia Ipnotica neoericksoniana Terzo manifesto teorico-didattico: update (AA.VV.) Ed Amisi 2001 (Italian)

30. Carmody TP, Duncan CL, Solkowitz SN, Huggins J, Simon JA. Hypnosis for smoking relapse prevention: a randomized trial. Am J Clin Hypn. 2017;60:159-71.

31. Keefer L, Palsson OS, Pandolfino JE. Best practice update: incorporating psychogastroenterology into management of digestive disorders. Gastroenterology. 2018;154:1249-57.

32. Booth S. Hypnosis in a specialist palliative care settingenhancing personalized care for difficult symptoms and situations. Palliat Care. 2020;14:1-11.

33. Rousseaux F, Bicego A, Ledoux D, Massion P, Nyssen A-S, Faymonville M-E, et al. Hypnosis associated with 3D immersive virtual reality technology in the management of pain: a review of the literature. J Pain Res. 2020;13:1129-38.

34. Vanderlinden J, Vandereycken W. The (limited) possibilities of hypnotherapy in the treatment of obesity. Am J Clin Hypn. 1994;36:248-57.

35. Berthoud H-R, Münzberg H, Morrison CD. Blaming the brain for obesity: integration of hedonic and homeostatic mechanisms. Gastroenterology. 2017;152:1728-38.

36. Winkelstein LB. Hypnosis, diet, and weight reduction. N Y State J Med. 1959;59:1751-6.

37. Stanton HE. Weight loss through hypnosis. Am J Clin Hypn. 1975;18:94-7.

38. Kirsch I, Montgomery G, Sapirstein G. Hypnosis as an adjunct to cognitive-behavioral psychotherapy: a meta-analysis. J Consult Clin Psychol. 1995;63:214-20.

39. Allison DB, Faith MS. Hypnosis as an adjunct to cognitivebehavioral psychotherapy for obesity: a meta-analytic reappraisal. 1996. In: Database of Abstracts of Reviews of Effects (DARE): quality-assessed reviews. York (UK): Centre for Reviews and Dissemination (UK); 1995. Available from: https://www.ncbi. nlm.nih.gov/books/NBK66645/

40. Kirsch I. Hypnotic enhancement of cognitive-behavioral weight loss treatments - another meta-reanalysis. J Consult Clin Psychol. 1996;64:517-9.

41. Sapp M, Obiakor F, Scholze S, Gregas AJ. Confidence intervals and hypnosis in the treatment of obesity. Aust J Clin Hypnother Hypn. 2007;28:25-33.

42. Cochrane G, Friesen J. Hypnotherapy in weight loss treatment. J Consult Clin Psychol. 1986;54:489-92.

43. Stradling J, Roberts D, Wilson A, Lovelock F. Controlled trial of hypnotherapy for weight loss in patients with obstructive sleep apnoea. Int J Obes. 1998;22:278-81.

44. Gelo OCG, Zips A, Ponocny-Seliger E, Neumann K, Balugani R, Gold C. Hypnobehavioral and hypnoenergetic therapy in the treatment of obese women: a pragmatic randomized clinical trial. Int J Clin Exp Hypn. 2014;62:260-91.

45. Häuser W, Hagl M, Schmierer A, Hansen E. The efficacy, safety and applications of medical hypnosis. Dtsch Arztebl Int. 2016;113:289-96

46.• Milling LS, Gover MC, Moriarty CL. The effectiveness of hypnosis as an intervention for obesity: a meta-analytic review. Psychol Conscious. 2018;5:29-45 This study performed two meta-analyses quantifying the effectiveness of hypnosis as an intervention for obesity and the impact of adding hypnosis to cognitive-behavioral therapy in producing weight loss. The 
findings suggest hypnosis is very effective in producing weight loss over a relatively short span of time.

47. Bo S, Rahimi F, Properzi B, Regaldo G, Goitre I, Ponzo V, et al. Effects of self-conditioning techniques in promoting weight loss in patients with severe obesity: a randomized controlled trial protocol. Int J Clin Trials. 2017;4:20-7.

48. Bo S, Rahimi F, Goitre I, Properzi B, Ponzo V, Regaldo G, et al. Effects of self-conditioning techniques (self-hypnosis) in promoting weight loss in patients with severe obesity: a randomized controlled trial. Obesity. 2018;26:1422-9.

49. Cioffi I, Gambino R, Rosato R, Properzi B, Regaldo G, Ponzo V, et al. Acute assessment of subjective appetite and implicated hormones after a hypnosis-induced hallucinated meal: a randomized cross-over pilot trial. Rev Endocr Metab Disord. 2020;21:411-20 This pilot trial suggests the possibility to modulate brain peptides implicated in the appetite regulation by hypnosis.

50. Bolocofsky DN, Spinler D, Coulthard-Morris L. Effectiveness of hypnosis as an adjunct to behavioral weight management. J Clin Psychol. 1985;41:35-41.

51. Barabasz M, Spiegel D. Hypnotizability and weight loss in obese subjects. Int J Eat Disord. 1989;8:335-41.

52. Bornstein PH, Devine DA. Covert modeling-hypnosis in the treatment of obesity. Psychotherapy: Theory, Research \& Practice. 1980;17:272-6.

53. Goldstein Y. The effect of demonstrating to a subject that she is in a hypnotic trance as a variable in hypnotic interventions with obese women. Int J Clin Exp Hypn. 1981 Jan;29(1):15-23.

54. Byom TK, Sapp M. Comparison of effect sizes of three group treatments for weight loss. Sleep Hypn. 2013;15:1-10.

55. Wadden TA, Flaxman J. Hypnosis and weight loss: a preliminary study. Int J Clin Exp Hypn. 1981;29:162-73.

56. Deyoub PL, Wilkie R. Suggestion with and without hypnotic induction in a weight reduction program. Int J Clin Exp Hypn. 1980;28:333-40.

57. https://www.clinicaltrials.gov/ct2/results?cond=hypnosis\&term= obesity \& cntry $=\&$ state $=\&$ city $=\&$ dist $=$. Accessed 27 Dec 2020

58. Scientific Research on Hypnosis \& Type 2 Diabetics-NGH.net. Available at: https://www.ngh.net/scientific-research-onhypnosis-type-2-diabetics/. Accessed 28 Mar 2021.

59. Sucala M, Schnur JB, Glazier K, Miller SJ, Green JP, Montgomery GH. Hypnosis there's an app for that: a systematic review of hypnosis apps. Int J Clin Exp Hypn. 2013;61:463-74.

60. Shapiro S, Weisbaum E. History of mindfulness and psychology. Oxford research encyclopedia of psychology, 2020. Available at: https://oxfordre.com/psychology/view/10.1093/acrefore/ 9780190236557.001.0001/acrefore-9780190236557-e-678. Accessed 18 Dec 2020.

61. Kabat-Zinn J. An outpatient program in behavioral medicine for chronic pain patients based on the practice of mindfulness meditation: theoretical considerations and preliminary results. Gen Hosp Psychiatry. 1982;4:33-47.

62. Kabat-Zinn J. Mindfulness-based interventions in context: past, present, and future. Clin Psychol. 2003;10:144-56.

63. Bishop SR, Lau M, Shapiro S, Carlson L, Anderson ND, Carmody J, et al. Mindfulness: a proposed operational definition. Clin Psychol. 2004;11:230-41.

64. Kabat-Zinn J. University of Massachusetts Medical Center/ Worcester, Stress Reduction Clinic. Full catastrophe living: using the wisdom of your body and mind to face stress, pain, and illness. New York: Delacorte Press; 1990.

65. Segal ZV, Williams JMG, Teasdale JD. Mindfulness-based cognitive therapy for depression: a new approach to preventing relapse. New York: Guilford Press; 2002.

66. Kristeller JL, Hallett CB. An exploratory study of a meditationbased intervention for binge eating disorder. J Health Psychol. 1999;4:357-63.
67. Kristeller J, Wolever RQ, Sheets V. Mindfulness-based eating awareness training (MB-EAT) for binge eating: a randomized clinical trial. Mindfulness. 2014;5:282-97.

68. Keng S-L, Smoski MJ, Robins CJ. Effects of mindfulness on psychological health: a review of empirical studies. Clin Psychol Rev. 2011;31:1041-56.

69. Grossman P, Niemann L, Schmidt S, Walach H. Mindfulnessbased stress reduction and health benefits. A meta-analysis. J Psychosom Res. 2004;57:35-43.

70. Hofmann SG, Sawyer AT, Witt AA, Oh D. The effect of mindfulness-based therapy on anxiety and depression: a metaanalytic review. J Consult Clin Psychol. 2010;78:169-83.

71. Leyland A, Rowse G, Emerson L-M. Experimental effects of mindfulness inductions on self-regulation: systematic review and meta-analysis. Emotion. 2019;19:108-22.

72. O'Reilly GA, Cook L, Spruijt-Metz D, Black DS. Mindfulnessbased interventions for obesity-related eating behaviours: a literature review. Obes Rev. 2014;15:453-61.

73. Kristeller JL, Wolever RQ. Mindfulness-based eating awareness training for treating binge eating disorder: the conceptual foundation. Eat Disord. 2011;19:49-61.

74. Leehr EJ, Krohmer K, Schag K, Dresler T, Zipfel S, Giel KE. Emotion regulation model in binge eating disorder and obesity - a systematic review. Neurosci Biobehav Rev. 2015;49: 125-34.

75. Lyzwinski LN, Caffery L, Bambling M, Edirippulige S. The relationship between stress and maladaptive weight-related behaviors in college students: a review of the literature. Am J Health Educ. 2018;49:166-78.

76. Lyzwinski LN, Caffery L, Bambling M, Edirippulige S. A systematic review of electronic mindfulness-based therapeutic interventions for weight, weight-related behaviors, and psychological stress. Telemed J E Health. 2018;24:173-84.

77. Framson C, Kristal AR, Schenk JM, Littman AJ, Zeliadt S, Benitez D. Development and validation of the mindful eating questionnaire. J Am Diet Assoc. 2009;109:1439-44.

78. Godsey J. The role of mindfulness-based interventions in the treatment of obesity and eating disorders: an integrative review. Complement Ther Med. 2013;21:430-9.

79. Katterman SN, Kleinman BM, Hood MM, Nackers LM, Corsica JA. Mindfulness meditation as an intervention for binge eating, emotional eating, and weight loss: a systematic review. Eat Behav. 2014;15:197-204.

80. Olson KL, Emery CF. Mindfulness and weight loss: a systematic review. Psychosom Med. 2015;77:59-67.

81. Tapper K. Can mindfulness influence weight management related eating behaviors? If so, how? Clin Psychol Rev. 2017;53:122-34.

82. Dunn C, Haubenreiser M, Johnson M, Nordby K, Aggarwal S, Myer S, et al. Mindfulness approaches and weight loss, weight maintenance, and weight regain. Curr Obes Rep. 2018;7:37-49.

83. Yu J, Song P, Zhang Y, Wei Z. Effects of mindfulness-based intervention on the treatment of problematic eating behaviors: a systematic review. J Altern Complement Med. 2020;26:666-79.

84. Carrière K, Khoury B, Günak MM, Knäuper B. Mindfulnessbased interventions for weight loss: a systematic review and meta-analysis. Obes Rev. 2018;19:164-77.

85. Rogers JM, Ferrari M, Mosely K, Lang CP, Brennan L. Mindfulness-based interventions for adults who are overweight or obese: a meta-analysis of physical and psychological health outcomes. Obes Rev. 2017;18:51-67.

86. Godfrey KM, Gallo LC, Afari N. Mindfulness-based interventions for binge eating: a systematic review and meta-analysis. J Behav Med. 2015;38:348-62.

87.• Ruffault A, Czernichow S, Hagger MS, Ferrand M, Erichot N, Carette $\mathrm{C}$, et al. The effects of mindfulness training on weight-loss and health-related behaviours in adults with overweight and 
obesity: a systematic review and meta-analysis. Obes Res Clin Pract. 2017;11:90-111 This study performed a meta-analysis of 12 randomized controlled trials investigating the effects of any form of mindfulness training on weight loss, impulsive eating, binge eating, or physical activity participation in adults with overweight and obesity. Results suggest that mindfulness training has short-term benefits on health-related behaviors.

88. Artiles RF, Staub K, Aldakak L, Eppenberger P, Rühli F, Bender $\mathrm{N}$. Mindful eating and common diet programs lower body weight similarly: systematic review and meta-analysis. Obes Rev. 2019;20:1619-27.

89. Lawlor ER, Islam N, Bates S, Griffin SJ, Hill AJ, Hughes CA, et al. Third-wave cognitive behaviour therapies for weight management: a systematic review and network meta-analysis. Obes Rev. 2020;21:e13013.

90. https://www.clinicaltrials.gov/ct $2 /$ results? cond= mindfulness $\&$ term $=$ obesity $\&$ cntry $=\&$ state $=\&$ city $=\&$ dist $=$ \&Search=Search. Accessed 27 Dec 2020.

91. Amaro H, Cortés DE, Garcia S, Duan L, Black DS. Video-based grocery shopping intervention effect on purchasing behaviors among Latina shoppers. Am J Public Health. 2017;107:800-6.

92. Craving and lifestyle management through mindfulness studystudy results-ClinicalTrials.gov. Available at: https:// clinicaltrials.gov/ct2/show/results/NCT01250509. Accessed 31 Mar 2021.

93. Daubenmier J, Epel ES, Moran PJ, Thompson J, Mason AE, Acree $\mathrm{M}$, et al. A randomized controlled trial of a mindfulnessbased weight loss intervention on cardiovascular reactivity to social-evaluative threat among adults with obesity. Mindfulness. 2019;10:2583-95.

94. Radin RM, Epel ES, Daubenmier J, Moran P, Schleicher S, Kristeller J, et al. Do stress eating or compulsive eating influence metabolic health in a mindfulness-based weight loss intervention? Health Psychol. 2020;39:147-58.

95. Levin ME, Petersen JM, Durward C, Bingeman B, Davis E, Nelson C, et al. A randomized controlled trial of online acceptance and commitment therapy to improve diet and physical activity among adults who are overweight/obese. Transl Behav Med. 2020. https://doi.org/10.1093/tbm/ibaa123 Online ahead of print.

96. Czepczor-Bernat K, Brytek-Matera A, Gramaglia C, Zeppegno P. The moderating effects of mindful eating on the relationship between emotional functioning and eating styles in overweight and obese women. Eat Weight Disord. 2020;25:841-9.

97. Felske A, Williamson T, Rash J, Telfer J, Toivonen K, Campbell T. Proof of concept for a mindfulness-informed intervention for eating disorder symptoms, self- efficacy, and emotion regulation among bariatric surgery candidates. Behav Med. 2020;1:14. https://doi.org/10.1080/08964289.2020.1828255 Online ahead of print.

98. Schnepper R, Richard A, Wilhelm FH, Blechert J. A combined mindfulness-prolonged chewing intervention reduces body weight, food craving, and emotional eating. J Consult Clin Psychol. 2019;87:106-11.

99. Pinto-Gouveia J, Carvalho SA, Palmeira L, Castilho P, Duarte C, Ferreira $\mathrm{C}$, et al. Incorporating psychoeducation, mindfulness and self-compassion in a new programme for binge eating (BEfree): Exploring processes of change. J Health Psychol. 2019;24:46679.

100. Jastreboff AM, Chaplin TM, Finnie S, Savoye M, StultsKolehmainen M, Silverman WK, et al. Preventing childhood obesity through a mindfulness-based parent stress intervention: a randomized pilot study. J Pediatr. 2018;202:136-142.e1.

101. Hanson P, Shuttlewood E, Halder L, Shah N, Lam FT, Menon V, et al. Application of mindfulness in a tier 3 obesity service improves eating behavior and facilitates successful weight loss. $\mathrm{J}$ Clin Endocrinol Metab. 2019;104:793-800.

102. Wnuk SM, Du CT, Van Exan J, Wallwork A, Warwick K, Tremblay L, et al. Mindfulness-based eating and awareness training for post-bariatric surgery patients: a feasibility pilot study. Mindfulness. 2018;9:949-60.

103. Spadaro KC, Davis KK, Sereika SM, Gibbs BB, Jakicic JM, Cohen SM. Effect of mindfulness meditation on short-term weight loss and eating behaviors in overweight and obese adults: a randomized controlled trial. J Complement Integr Med. 2017;15.

104. Adler E, Dhruva A, Moran PJ, Daubenmier J, Acree M, Epel ES, et al. Impact of a mindfulness-based weight-loss intervention on sleep quality among adults with obesity: data from the SHINE randomized controlled trial. J Altern Complement Med. 2017;23:188-95.

105. Palmeira L, Pinto-Gouveia J, Cunha M. Exploring the efficacy of an acceptance, mindfulness \& compassionate-based group intervention for women struggling with their weight (Kg-Free): a randomized controlled trial. Appetite. 2017;112:107-16.

106. Raja-Khan N, Agito K, Shah J, Stetter CM, Gustafson TS, Socolow H, et al. Mindfulness-based stress reduction in women with overweight or obesity: a randomized clinical trial. Obesity. 2017;25:1349-59.

107. Levoy E, Lazaridou A, Brewer J, Fulwiler C. An exploratory study of mindfulness-based stress reduction for emotional eating. Appetite. 2017;109:124-30.

108. Spijkerman MPJ, Pots WTM, Bohlmeijer ET. Effectiveness of online mindfulness-based interventions in improving mental health: a review and meta-analysis of randomised controlled trials. Clin Psychol Rev. 2016;45:102-14.

109. Jayawardene WP, Lohrmann DK, Erbe RG, Torabi MR. Effects of preventive online mindfulness interventions on stress and mindfulness: a meta-analysis of randomized controlled trials. Prev Med Rep. 2016;5:150-9.

110. Lyzwinski LN, Edirippulige S, Caffery L, Bambling M. Mindful eating mobile health apps: review and appraisal. JMIR Mental Health. 2019;6:e12820.

111. De Benedittis G. Neural mechanisms of hypnosis and meditation. J Physiol Paris. 2015;109:152-64.

112. Otani A. Hypnosis and mindfulness: the twain finally meet. Am J Clin Hypn. 2016;58:383-98.

113. Lifshitz M, Raz A. Hypnosis and meditation: vehicles of attention and suggestion. J Mind Body Regul. 2012;1:3-11.

114. Lynn SJ, Surya Das L, Hallquist MN, Williams JC. Mindfulness, acceptance, and hypnosis: cognitive and clinical perspectives. Int J Clin Exp Hypn. 2006;54:143-66.

115. Lynn SJ, Barnes S, Deming A, Accardi M. Hypnosis, rumination, and depression: catalyzing attention and mindfulness-based treatments. Int J Clin Exp Hypn. 2010;58:202-21.

116. Lynn SJ, Malakataris A, Condon L, Maxwell R, Cleere C. Posttraumatic stress disorder: cognitive hypnotherapy, mindfulness, and acceptance-based treatment approaches. Am J Clin Hypn. 2012;54:311-30

117. Elkins GR, Olendzki N. Mindful hypnotherapy: the basics for clinical practice. New York: Springer Publishing Company, LLC.; 2019.

118. Grover MP, Jensen MP, Patterson DR, Gertz KJ, Day MA. The association between mindfulness and hypnotizability: clinical and theoretical implications. Am J Clin Hypn. 2018;61:4-17.

Publisher's Note Springer Nature remains neutral with regard to jurisdictional claims in published maps and institutional affiliations. 